\title{
Crime Scene Investigation Issues: Present Issues and Future Recommendations
}

\author{
KHAIRUL Osman \\ Gina FRANCESCA GaBRIEL \\ NOOR HAZFALINDA HAMZAH
}

\begin{abstract}
Crime Scene Investigation is the backbone of any criminal investigation. Expert report generated by Crime Scene Investigators are based on scientific evidence and are reported in a standard form. The content, when published should be reviewed rigorously by its peers. The expert report is a document detailing out how the investigation process of a crime scene was performed. The process of collecting and evidence processing do not only entail identifying, collecting and storing evidences for later analysis but it is a step by step process that is well structured in a document called Standard Operating Procedure (SOP) for Crime Scene Investigator. SOP is a complex document and sometimes overwhelmingly technical for the uninitiated. But if understood, it can be a good guide for law practitioners to determine if a piece of evidence should be included in a case. This article details out the SOP which entails groundwork before entering a crime scene, processing of a crime scene and wrapping up of the crime scene investigation. At each step, this paper will look at how it is adopted in current practices, its weakness and suggested improvement that should be adopted to ensure a final quality expert report.
\end{abstract}

Keywords: Crime scene investigation; SOP; expert report; investigation; scientific evidence

\section{INTRODUCTION}

Crime scene investigation is a major component of criminal investigation used commonly but not exclusively when there is a presence of a heinous crime. Utilizing physical evidence found at the scene, deductive and inductive reasoning allows the forensic scientist to roughly reconstruct events surrounding the crime. ${ }^{1}$ As this field is multidisciplinary - ranging from arts to science, understanding the scientific process and eventually, the expert report which includes crime scene reconstruction can sometimes be daunting for the uninitiated. $^{2}$

Management during an investigation of a crime scene go hand in hand to ensure the reconstruction of a crime is based on scientific evidence and not possible outcomes. To ensure that this ideal is upheld, all evidence collection including witness testimony, crime scene photographs, physical exhibits, on-site analysis of exhibits, and analysis of the crime scene itself must be done in an impartial way to ensure acceptance beyond reasonable doubt in court. ${ }^{3}$

Skill, knowledge and attitudes of crime scene investigators will determine the strength and potential weakness of an investigation. ${ }^{4}$ Insufficient sampling size of evidence or an improper randomized sampling method will certainly misrepresent the crime that had happened. This is irrespective of how well an analysis is done in a forensic laboratory. Hence, the terminology garbage in, garbage out.

\section{CRIME SCENE INVESTIGATION UNIT}

Currently, there are numerous Crime Scene Investigation Units scattered through the various enforcement agencies in the Malaysian government. Each unit is tasked to process different types of crime scene ranging from abused children, killing on the high seas, poaching and construction mishaps. Despite the wide range of function, their fundamental Standard Operating Procedure (SOP) still remain relatively the same. ${ }^{5}$

Most developing and developed countries follow a modified U.S. Army Criminal Investigation Command (USACIDC) Standard Operating Procedure (SOP) for crime scene investigation. ${ }^{6}$ Generally, the SOP is divided into three sequential steps - the pre-crime, crime and post-crime investigation.

Discussion on how each step is conducted in an investigation, its strength and weakness and possible future improvement will be discussed thoroughly in this paper. Reference to the weakness and strength does not infer to specific enforcement agencies but rather a general 
observation that was deduced during conducting, assisting and consulting investigation, and running specialized crime scene training for the past 30 years for local and international enforcement agencies.

\section{PRE-CRIME SCENE}

The pre-crime scene covers 3 steps. The first is called an initial notification. In this step, a written or verbal instruction from an investigating officer (IO) to conduct a crime scene investigation must occur. Documentation of who gave and who received the instruction, date and time, when the instruction was made, must be documented by the lead Crime Scene Investigator (CSI) in their logbook. In Malaysia, this is done without fail by both the lead CSI and IO. In theory, once the lead CSI prepares a Crime Scene Investigation Expert Report, this information will be transferred and made formal. $^{7}$

We feel that this procedure is weak as when an instruction is given orally, a concrete proof that the instruction was made is questionable as no tangible proof is available. In the future, we recommend that all verbal instruction must be recorded in writing and stored as evidence. Additional instructions from the IO or senior officers must also be recorded thus allowing prosecution and defence to summon them as a witness in court.

The actual pre-crime phase starts only when an IO officially hands over a crime scene to a lead CSI after giving instruction to conduct a scientific investigation. The function of a crime scene investigation team will then end when there is a formal handing over of the scene to an official $\mathrm{IO}$ by the head of the crime scene investigation team. ${ }^{8}$ Scene hand over must be done officially thus a formal document stating the date, time and officials that were involved in the handling over must be present. ${ }^{9}$

The two instructions mentioned in the two previous paragraphs may sound similar, but in fact, they cover two distinctive sets of instructions. The first one would contain an instruction to start what type of crime scene investigation, and the second, a formal handing over of a crime scene. Suggested demarcation area of the crime scene area can be made by the IO, although the suggestion would be taken at face value and not an order. ${ }^{10}$ Currently, these two instruction components are assumed to be the same hence would open up to a flaw in the investigation process that is often overlooked in justice. For example, a car had ploughed through a riverbank and ran into the river. If the IO intended to hide the crime, he would likely ask a tow truck operator to pull the car out of the river and instruct the CSI to investigate the car. By doing this, evidence that may have been present at the river bank and the bottom of the river may be lost. If these two instructions are documented separately, a re-examination of the case would indicate that the IO could have played an important role in hiding the crime.

Step two is known as Coordination, Assessment, and Team Call-Out. This step refers to the planning of the CSI on how they would conduct their investigation. This discussion is usually lead by the CSI lead and assisted by the second most senior CSI. The composition of the CSI team varies between the strength of the team, the size of the scene and the presumptive crime that had occurred. ${ }^{11}$ In general, there should be at least three to four CSI officers. Their function would cover but not limited to the leader of the CSI team, forensic photographer, crime scene sketcher, documenter and evidence collector. ${ }^{12}$

Each officer's function may change between crime scenes at the discretion of the lead CSI. Allocation of a function must be documented and there should be at least a verbal confirmation that each member had accepted their designated function. Thus, each CSI member would have an equal probability to be called to court as an expert witness. ${ }^{13}$

Currently, the selection of CSI function is based on the experience of past assignments. No formal training, assessment of knowledge and capability are done in a proper way. Thus, allowing sub-standard work and questionable results. Internal of capability should always be avoided as it would lead to questionable certification. Third-party assessment who hold no obligation or bias to the officer or enforcement organization must be utilised. ${ }^{14}$ Enforcement agencies must take this issue seriously as questionable evidence would certainly lead to a dismissal of the case.

The final component of this stage is known as Conducting Initial Observation. This section would cover: (1) Conducting an initial scan; and (2) Setting up a cordoned area. The initial scan is 
conducted by each member of the investigation team. They are not supposed to enter the "crime scene' nor touch any evidence. Observation must be done from afar to identify victims, central theme items, and fragile evidence. Utilization of multiple eyes to scan the crime scene from multiple directions would hopefully avoid the occurrence of tunnel vision. A discussion must be done after the activity and a strategy on how to approach the scene must be suggested and finally decided by lead CSI. ${ }^{15}$

Currently, the process of discussion and final decision within the CSI team is not documented. Decisions made related to the crime scene can only be inferred through the expert report or notation in the lead CSI's notebook if any. Future improvement should include a recording of the discussion as this would be useful for training budding CSI purposes and continuous training of operational CSI.

Once the discussion is completed and a final decision on how to enter the scene is determined, a cordoned area bigger than where potential evidence would be present should be set up. Consideration of what crime had probably occurred would also be taken into consideration when deciding how large an area the cordoned would cover. $^{16}$ Even though the cordoned area is only set after numerous discussion and instructions, the security of the area should be made top priority by the primary responder. The cordoned area should be smaller than the secured area created by the primary responders.

Currently, this secure area is not enforced rigidly resulting in multiple individuals trespassing on the crime scene. Documentation of trespassers is not executed thus allowing the prosecution to question the validity of the evidence at hand. Presence of reporters taking multiple pictures at various angles involving various high profile cases, clearly shows that the issue of crime scene integrity is frequently breached. It is hoped that future training for primary responders should impress the importance of this matter.

In further reference to the issue of the cordoned area, submission of a crime scene expert report should contain two important set of information: (1) Details of entry into the scene; and (2) Details of exit from the scene. Between these two aforementioned- entry and exit from the crime scene are restricted to the crime scene investigation team only. Any deviation from this rigid rule would result in a compromised crime scene and would lead to issues of the presence of questionable evidence. ${ }^{17}$ Officers or individual listed as active CSI in the case can be called to court as an expert witness. On the other hand, any individuals not classified as active CSI in the case present within the area should be considered trespassers. They may be called in court as a witness. Currently, the integrity of cordoned area is taken lightly as reflected by numerous crime news report pictures which clearly depicts officers and untrained CSI officers milling about the scene. Future action should be taken to secure the scene thoroughly by having a video recording running throughout the crime scene investigation session.

\section{CRIME SCENE}

The crime scene phase is composed of 11 sequential steps covering - dealing with the deceased, photographing scene, document overall observation, scene sketch, conduct first check, release body, collect items of evidence, conduct a second, and the third recheck of the scene and finally check beyond the scene. ${ }^{18}$

Processing of evidence on a deceased body is covered under the Criminal Procedure Code 593 Act sub-section 330. Under this law, the examination of a deceased body must be done by a registered medical doctor. Due to this, any evidence attached to or inside the body will be processed by an appointed doctor/ forensic pathologist. Furthermore, an expert report relating to the cause of death, biochemical results and any related issue must be provided by the doctor/ pathologist to the IO in due time. We feel that the interpretation of this law is often misread by the CSI. Although the demarcation of the function is clearly stated, CSI tend not to process the deceased body at all. In truth, it is within their right to collect evidence present around and under the body. This would include broken fingernails, detached footwear, or valuables. Wrapping the deceased extremities in brown paper bags, or any exposed appendages must be done to ensure important biological materials are not lost during transport from the crime scene to an autopsy table. This issue should be addressed particularly death due to violent crime. 
Photographing a crime scene must be done to support these functions: (1) to provide an overall layout of the crime scene; (2) location of each evidence with other evidence; (3) location of each evidence to an immovable structure in the crime scene; and (4) the characteristics of each evidence at a macroscopic level..$^{19}$ Based on this, a long, medium and close-up shots must be taken for each evidence with unique tagging clearly visible. $^{20}$

Each time a picture of an evidence is taken, a file name of the image and label must be recorded in a photography logbook and eventually declared in the appendix of the expert report. Any unfocused or irrelevant images taken must also be declared to ensure the issue of non-disclosure is not raised in court. Currently, as the images are taken using one SLR-camera, images are labelled sequentially, and each image file will contain sequential metadata of date and time..$^{21}$ As image data are recorded digitally, the possibility of data manipulation is highly possible. To ensure this does not occur, future CSI should be geotagged and digitally signing each file and note down the digital signature, in both the photography logbook and the expert report appendix. Lawyers noticing non-sequence of image file name, absence of geotagging data in the image and dissimilar digital signature between the presented evidence and the logbook, should question the irregularities in court as there could be a high possibility of non-disclosure of evidence.

Unlike the initial observation step, this step would require CSI officers to describe the scene in detail. The description would provide a window on how the lead CSI interprets the scene. Currently, this step is usually overlooked and is reported poorly. Current best practices used by developed countries is known as the eight-step descriptive method. This method entails the investigator describing the scene containing these important descriptions: (1) Quantity; (2) Item; (3) Colour; (4) Type of construction; (5) Approximate size; (6) Identifying features; (7) Condition; and (8) Location. The information narrated out from this section can then collaborate from photography logbook and crime scene sketching. As each one is done by a different CSI officer, discrepancies can be identified by the IO and court. Although this is an additional work but it provides significant advantages in term of collaboration of data. Hence, this additional step should be adopted in the near future.

Scene sketching is a process of reconstructing the scene in two dimensions. Sketching should be done when the scene is at a pristine stage whereby the position of evidence had not been moved. Utilizing distance of immovable objects (doorway, windows, pillars etc.) to evidence, reconstruction of the crime scene again when the scene has been released and cleared up can be done. This would be very useful when the court requires to visit the scene during a trial. Presence of a detailed crime scene on paper would also allow the IO, Attorney General (AG), prosecution and defence to confirm if the expert report, photography logbook, initial observation notes and other related notes correlate with each other. Until today, scene sketching by CSI seemed to be done satisfactorily but we have found that this step requires a lot of time to complete thus delaying the release of crime scene. ${ }^{22}$ In future, the use of 3D-mapping equipment would probably solve this problem although the cost would probably be a prohibitive issue.

At this stage, all search effort has been done visually and at a distance. Important evidence that needs to be collected has been noted, photographed, described and sketched. The first recheck would encompass reviewing the evidence again closely and if additional evidence is found, CSI officers are required to return to step 5 (scene photography). Currently, we have not noted any deviation of this protocol hence no future improvement recommendation can be suggested.

When to allow a body to be taken out from a crime scene? This largely depends on the issues of: (1) Undue exposure; (2) Ethical; and (3) Humanity. A body lying in the middle of the road when passers-by can take pictures and upload them to any social network would not be ethically correct. Hence, when the body that had been photographed, an overall observation had been conducted and sketching completed, the body can now be taken out from the scene by the appointed pathologist from the Institut Perubatan Forensik Negara $\left(\right.$ IPFN). ${ }^{23}$ It is recommended that this action is done in discussion between the forensic pathologist onsite and the lead CSI. The issue of who owns the deceased has never been 
a problem in Malaysia. Pathology report (expert report) on a body by IPFN members has also been generally accepted by the court without much objection from both legal parties.

Despite this, in situ documentation of a body before it is placed into a body bag is not done thoroughly at crime scenes. Hence the possibility of a piece of artefact evidence created during transport can occur. This can later accidentally be construed as an overlook evidence. In future, it is recommended that photograph documentation around the body before and during the placement of the body into the body bag must be done. Any observation by the lead CSI must be noted in the lead CSI notebook. These notations include observation of passive blood flow movement from wounds and observed smears in an original unstained area of the body.

Collection of evidence requires CSI to place each item found in a container suitable for it be analysed for a particular factor. For example, a bloody knife could be collected and sent to the forensic lab to be analysed for DNA, the blade for wound comparison and the knife handle for fingerprints. So it is very important that the processing of evidence must be done before it is placed into a suitable container. ${ }^{24}$ Currently, most CSIs are well versed on how to store evidences but mostly are not concerned with what numerous potential information that a piece of collected evidence can produce. When this occurs, unintentional partial / complete destruction of an evidence will occur. An example would be an apple with bite marks on it. To obtain as much information from this evidence, CSIs should create a dental cast on the bite mark, dust the smooth area of the fruit for fingerprint and swab possible dried saliva for DNA. All should be done on-site. Putting the apple in a brown evidence bag without doing the aforementioned steps would probably destroy the DNA and bite mark evidence due to the presence of polyphenol oxidase (PPO) and other digestive enzymes present inside saliva. ${ }^{25}$

Transferring evidence from were an evidence lay to a predetermined container for safekeeping is commonly practised by most CSI teams. In truth, this action has the potential to expose the evidence to contamination. An important rule of thumb is to always take the container to the evidence, not evidence to the container. ${ }^{26}$ This rule should be habitually applied in future practice and training of new CSI. At this stage, all evidences should have been collected and stored. This would allow a more intrusive examination of the crime scene. This stage is known as the second recheck of the crime scene.

By utilizing alternative light source (ALS), CSI should be able to identify missed body fluids and fibres that are invisible under white light. ${ }^{27}$ Moving of items, digging down into a container looking at surfaces not available during a cursory examination, opening of items and dismantling will occur at this stage. Currently, this is done together during step 8 (first recheck of the scene). This should not occur as this would cause the evidence to be moved thus exposing it to potential contamination. Hence, future CSI should follow the steps laid out in the SOP habitually.

Step 12 is known as the third recheck of the crime scene. A CSI should be confident that they have done a good job when they are unable to find any new evidence as this step. Once this is completed, a more disruptive technique may be used. This covers the use of luminol, amido-black enhancement and external ballistic examinations. Currently, not much comment can be made at this step. But, we have noticed that ballistics examination are not done by ballistic experts but by CSI with some basic knowledge in this area. In the future, enforcement agencies should develop certified ballistic reconstruction experts within their organization. This would allow a more confident expert report with minimal question towards the validity of the crime scene interpretation by members of the court. 28

Check beyond the crime scene should be done as the next step. Although due diligence had been done during the initial assessment, CSI might have overlooked evidence scattered leading to the main crime scene. ${ }^{29}$

When this occurs, a secondary crime scene should be created. ${ }^{30}$ We have noticed, routinely this does not occur. CSs I tend to expand the area of the primary crime scene to include the first scene. This action is incorrect as, during the processing of the primary crime scene, the secondary crime scene was not protected. The issue of tainting of evidence found in the new site could occur. In the future, a buffer zone 
should be created when a primary crime scene has been identified. By doing this, opening a secondary crime scene should not be an issue as scene security had been maintained throughout the investigation. Opening a secondary crime scene should also not be perceived that due diligence on the part of lead CSI was not done in the early part of an investigation, rather than the desire of the lead CSI to be more thorough in his/ her investigation.

Before releasing the scene, lead CSI and its members should review all activities done previously, discussed what was not done and why. We recommend that this step should be documented and possibility recorded as it would be used as preparation when the CSI members are called to court.

\section{POST-CRIME SCENE}

Releasing of a crime scene is an important first step to hand over the crime scene to the IO. Once released, CSIs are not allowed to collect any evidence or enter the scene without proper instruction from the attending IO. Detailed documentation related to the transfer of the scene must be noted inside the lead CSI logbook. This must include but not restricted to date and time of transfer and name of parties involved with the transfer.

Step 16 involves the process and packing of evidence. Processing can be done while the collection of evidence is completed (step 10). The need to do this is usually due to the fragility of the evidence. All evidence must be stored in its own individual container, has its own chain of evidence form, the container selected must be suitable and correspond to the evidence which will be analysed when it arrives at the forensic laboratory. The integrity of the container storing the evidence is essential as improper packing will raise the issue of tainted evidence. Current and future CSI should also take note that for each evidence collected; all $\operatorname{logs}$ in forensic photographer log, evidence log and scene sketch should contain a clear reference to the evidence. Each evidence should have a short, medium and long-distance shots in the forensic photographer's camera which is then written down in the forensic photographer log.

The final step is a formal debriefing and is highly recommended to be done within 24 hours.
During this discussion, all parties including IO, CSI members and sometimes first responders should sit together to review what had been done by all parties. ${ }^{31}$ CSI is not obligated to document what is discussed. In the future, a recording of the discussion should be done to allow other CSI to review what has transpired and how the process could be improved further in the future.

\section{CONCLUSION}

In a nutshell, it is quite clear that more work has to be done in redesigning forensic science program syllabus for future CSI and retraining practising CSI. The attitude of personnel towards the work-life and desire to rack up enough time presenting evidence in court as an expert witness is important when selecting new CSI officers. Most current practising CSI seemed to have a positive attitude towards improving their capability and function. ${ }^{32}$ So, it is strongly suggested that upper management of various enforcement agencies should take a serious view on this matter. Retraining, upgrading, re-education and periodic certification of CSI staff is essential to ensure that a crime that occurs can be solved quickly without compromising quality or the outcome. In the end, a badly collected evidence will only produce inconclusive result - garbage in, garbage out.

\section{NOTES}

Horswell, J., Crime scene investigation, in The Practice of Crime Scene Investigation. 2016, CRC Press. p. 29-72.

2 Crispino, F., Nature and place of crime scene management within forensic sciences. Science \& Justice, 2008. 48(1): p. 24-28.

3 Gehl, R. and D. Plecas, Introduction to criminal investigation: processes, practices and thinking. 2017: Justice Institute of British Columbia.

4 Horswell, J., The practice of crime scene investigation. 2004: CRC Press.

5 Fish, J.T., et al., Crime scene investigation. 2013: Routledge.

6 Geberth, V.J., Practical homicide investigation: Tactics, procedures, and forensic techniques. 2016: CRC Press.

7 Gardner, R.M., Practical crime scene processing and investigation. 2011: CRC Press.

8 Cook, T. and A. Tattersall, Blackstone's senior investigating officers' handbook. 2010: Oxford University Press Oxford.

9 Julian, R., S. Kelty, and J. Robertson, "Get it right the first time": Critical Issues at the Crime Scene. Current issues in criminal justice, 2012. 24(1): p. 25-37. 
10 Baxter Jr, E., Complete crime scene investigation handbook. 2015: CRC press.

11 Dutelle, A.W., An introduction to crime scene investigation. 2014: Jones \& Bartlett Publishers.

12 Maloney, M.S., D. Housman, and R.M. Gardner, Crime Scene Management, in Crime Scene Investigation Procedural Guide. 2014, CRC Press. p. 40-43.

13 PP v. KANAGESWARAN SIWAPIRKASAM. 2015, HIGH COURT MALAYA, ALOR SETAR; PP v. SYARAFI ABU, in Tamby, N. 2017, HIGH COURT MALAYA, TAIPING; State v. Marshall. 2020, SC: Court of Appeals.

14 Meyers, M. and M. Rogers, Computer forensics: The need for standardization and certification. International Journal of Digital Evidence, 2004. 3(2): p. 1-11.

15 Julian, R., S. Kelty, and J. Robertson, Get it right the first time: critical issues at the crime scene. Current Issues Crim. Just., 2012. 24: p. 25.

16 Ribaux, O., et al., Intelligence-led crime scene processing. Part II: Intelligence and crime scene examination. Forensic science international, 2010. 199(1-3): p. 63-71.

17 Jobela, N.K., The significance of efficient murder crime scene processing. 2019.

18 Singh, S., An evaluation of the role of forensic science in crime scene reconstruction. 2018.

19 Duncan, C.D., Advanced crime scene photography. 2015: CRC Press.

20 Lee, H.C., T. Palmbach, and M.T. Miller, Henry Lee's crime scene handbook. 2001: Academic Press.

${ }^{21}$ Robinson, E.M., Crime scene photography. 2016: Academic Press.

22 Levi-Minzi, M. and M. Shields, Serial sexual murderers and prostitutes as their victims: Difficulty profiling perpetrators and victim vulnerability as illustrated by the Green River case. Brief Treatment and Crisis Intervention, 2007. 7(1): p. 77

23 Fisher, B.A. and D.R. Fisher, Techniques of crime scene investigation. 2003: CRC Press.

24 Gardner, R.M. and D. Krouskup, Practical crime scene processing and investigation. 2018: CRC Press.

25 Aydin, B., I. Gulcin, and S.H. Alwasel, Purification and characterization of polyphenol oxidase from Hemşin apple (Malus communis L.). International journal of food properties, 2015. 18(12): p. 2735-2745.

26 Lyman, M.D., Criminal investigation: The art and the science. 2001: Prentice Hall.

27 Virkler, K. and I.K. Lednev, Analysis of body fluids for forensic purposes: from laboratory testing to nondestructive rapid confirmatory identification at a crime scene. Forensic science international, 2009. 188(1-3): p. 1-17.

28 Buck, U., et al., 3D bloodstain pattern analysis: ballistic reconstruction of the trajectories of blood drops and determination of the centres of origin of the bloodstains. Forensic science international, 2011. 206(1-3): p. 22-28.

29 Barksdale, L., Crime Scene Investigation Protocol. 2007.

30 Karmy-Jones, R., et al., Bomb-related injuries. Military medicine, 1994. 159(7): p. 536-539

31 Scott, A.M., Crime Scene Management. Wiley Encyclopedia of Forensic Science, 2009.
32 Kelty, S.F., R. Julian, and J. Robertson, Professionalism in crime scene examination: the seven key attributes of top crime scene examiners. Forensic science policy \& management: an international journal, 2011. 2(4): p. 175-186.

\section{REFERENCES}

Aydin, B., Gulcin, I. and Alwasel, S. H. 2015. Purification and characterization of polyphenol oxidase from Hemşin apple (Malus communis L.). International Journal of Food Properties 18(12): 2735-2745.

Barksdale, L. 2007. Crime Scene Investigation Protocol.

Baxter Jr, E. 2015. Complete Crime Scene Investigation Handbook. CRC Press.

Buck, U. et al. 2011. 3D bloodstain pattern analysis: ballistic reconstruction of the trajectories of blood drops and determination of the centres of origin of the bloodstains. Forensic Science International 206(1-3): 22-28.

Cook, T. and Tattersall, A. 2010. Blackstone's Senior Investigating Officers' Handbook. Oxford University Press Oxford.

Crispino, F. 2008. Nature and place of crime scene management within forensic sciences. Science \& Justice 48(1): 24-28.

Duncan, C.D. 2015. Advanced Crime Scene Photography. CRC Press.

Dutelle, A.W. 2014. An Introduction to Crime Scene Investigation. Jones \& Bartlett Publishers.

Fish, J.T. et al. 2013. Crime Scene Investigation. Routledge.

Fisher, B.A. and Fisher, D. R. 2003. Techniques of Crime Scene Investigation. CRC Press.

Gardner, R.M. 2011. Practical Crime Scene Processing and Investigation. CRC Press.

Gardner, R.M. and Krouskup, D. 2018. Practical Crime Scene Processing and Investigation. CRC Press.

Geberth, V. J. 2016. Practical Homicide Investigation: Tactics, Procedures, and Forensic Techniques. CRC Press.

Gehl, R. and Plecas, D. 2017. Introduction to Criminal Investigation: Processes, Practices and Thinking. Justice Institute of British Columbia.

Horswell, J. 2016. Crime Scene Investigation, in the Practice of Crime Scene Investigation. CRC Press.

Horswell, J. 2004. The Practice of Crime Scene Investigation. CRC Press.

Jobela, N. K. 2019. The Significance of Efficient Murder Crime Scene Processing.

Julian, R., Kelty, S. and Robertson, J. 2012. "Get it right the first time": Critical issues at the crime scene. Current Issues in Criminal Justice 24(1): 25-37.

Karmy-Jones, R. et al. 1994. Bomb-related injuries. Military Medicine 159(7): 536-539. 
Kelty, S. F., Julian, R. and Robertson, J. 2011. Professionalism in crime scene examination: the seven key attributes of top crime scene examiners. Forensic Science Policy \& Management: An International Journal 2(4): 175-186.

Lee, H.C., Palmbach, T. and Miller, M. T. 2001. Henry Lee's Crime Scene Handbook. 2001: Academic Press.

Levi-Minzi, M. and Shields, M. 2007. Serial sexual murderers and prostitutes as their victims: Difficulty profiling perpetrators and victim vulnerability as illustrated by the Green River case. Brief Treatment and Crisis Intervention 7(1): 77.

Lyman, M.D. 2001. Criminal Investigation: The Art and the Science. Prentice Hall.

Maloney, M.S., Housman, D. and R.M. Gardner, R. M. 2014. Crime Scene Management, in Crime Scene Investigation Procedural Guide. CRC Press.

Meyers, M. and Rogers, M. 2004. Computer forensics: The need for standardization and certification. International Journal of Digital Evidence 3(2): 1-11.

$P P$ v. KANAGESWARAN SIWAPIRKASAM. 2015, HIGH COURT MALAYA, ALOR SETAR;

$P P$ v. SYARAFI ABU, in Tamby, N. 2017, HIGH COURT MALAYA, TAIPING; State v. Marshall.

2020, SC: Court of Appeals.

Ribaux, O. et al. 2010. Intelligence-led crime scene processing. Part II: Intelligence and crime scene examination. Forensic Science International 199 (1-3): 63-71.
Robinson, E.M. 2016. Crime Scene Photography. Academic Press.

Scott, A.M. 2009. Crime Scene Management. Wiley Encyclopedia of Forensic Science.

Singh, S. 2018. An Evaluation of the Role of Forensic Science in Crime Scene Reconstruction.

Virkler, K. and Lednev, I. K. 2009. Analysis of body fluids for forensic purposes: from laboratory testing to non-destructive rapid confirmatory identification at a crime scene. Forensic Science International 188(1-3): 1-17.

Khairul Osman

Fakulti Sains Kesihatan

Universiti Kebangsaan Malaysia

43600 UKM Bangi, Selangor

Email: khairos@ukm.edu.my

Gina Francesca Gabriel

Fakulti Sains Kesihatan

Universiti Kebangsaan Malaysia

43600 UKM Bangi, Selangor

Noor Hazfalinda Hamzah

Fakulti Sains Kesihatan

Universiti Kebangsaan Malaysia

43600 UKM Bangi, Selangor 